\title{
The extraction method of the traditional architectural culture
}

\author{
Li Xing
}

Sichuan International Studies University, Sichuan, China

Keywords: China, France, Traditional architecture

\begin{abstract}
China and the European civilization formed in France, the comparison between traditional architecture development and research is of great significance in the field of culture and history. France is a shining pearl on the European continent, while China has nearly five thousand years of history of civilization. Research on the method of the traditional architecture, is actually thinking about Chinese and French culture. The receptivity and interlinked, even result in different cultural roots under all kinds of buildings.
\end{abstract}

Human architectural history can be traced back to nearly five thousand BC in hemudu site in China. In this period of history, the development of the building with society, culture, history and the change of its diversity. In each art building is one of the earliest art. Engels thought in the late primitive society, has been "as the construction of art". Architecture is a mirror of The Times, it reflects a in the form of a unique era, a nation's aesthetic. Architectural art shows human creation of material civilization, it is known as "frozen music", the "three-dimensional painting", and "invisible" stone written history".

\section{In the development of the traditional architecture}

When we say to the world of traditional architecture, China and France have their striking place. Is elegant, noble, romantic French architecture; It pursuit of poetic and artistic concept, this greatly influenced its characteristics. In ancient architecture system, China has long maintained its unique structure, layout, aesthetics, etc.

From the point of the origin of Chinese architecture, the han people's gathering place mainly adopts wood for building materials. Using connection of courtyard space structure and complex courtyard houses. The construction mode is mainly used in houses, rather than religious buildings or royal palaces. And on select material, European architecture including French traditional architecture is given priority to with masonry structure.

In 221 BC, qin shi huang established a centralized empire, he built the palace and the mausoleum in xianyang, since this consumes a lot of labor and financial resources. The Great Wall, canals, capital and so on these buildings took tens of thousands of human resources. In the end, the qin dynasty as a result of extreme luxury, lack of Qian Shaobing perish. In the han dynasty, the emperor also began to build the palace, for instance changan JianZhang palace, then built the luoyang city. Due to national unity and prosperity, this is the first peak in the history of Chinese architecture 。

Wei jin northern and southern dynasties is the stage of national integration, began to enter the Chinese buddhist architecture, at this time, the pagoda and the temple is very popular. Many areas are digging the buddhist grottoes, such as the yungang grottoes, dunhuang mogao grottoes, the longmen grottoes of luoyang, and so on. At that time the Chinese building into a little India and west Asia architectural style.

However this period of France is still in its national migration and infighting, established the unified frankish kingdom until 481, the French architecture to develop gradually 。

The second boom of traditional Chinese architecture in the sui and tang dynasties, the architecture inherited the achievements of the past and been influenced by foreign styles. The architectural style of sui and tang dynasties spread to Japan and Korea and its influence. Zhaozhou bridge, Buddha temple, the wild goose pagoda is the representative work of that era. At that time the construction technology is very advanced. 
At this point, Europe has step into the middle ages. From Roman architectural style and the gothic. Roman architecture originated from Caroline type building, and development together with the otto style buildings. Roman architecture in different areas have their own development period in France. The languedoc region in 1130 reached its peak and Burgundy regions; The twelfth century, in the auvergne area, it developed into a kind of special style; Finally, in the thirteenth century, southeastern region also has a significant development. After entering in the second half of the middle ages, European gothic architecture begins popularity. It was born in the 12th century French island, this originated in France inherited Romanesque architecture characteristics, the architecture of development until the 16th century.

Last a period of development of traditional Chinese architecture is in the 15th century to the 17th century, private garden and the royal garden have begun to emerge: the Summer Palace, the Summer Palace, the suzhou gardens are world famous garden. Temples and palaces, gardens and is an important part of ancient Chinese architecture.

Europe right now is in the Renaissance, the Renaissance style of architecture originated in Italy, and at the beginning of the 15th century to the early 17th century in France and other European countries. It is a combination of ancient Greek and Roman culture and thought. Architects think, the classical architecture of the ancient Greek and Roman especially classical pillar type composition embodies the harmony and rational, and have in common with the human body beauty, these are in conformity with the Renaissance humanism ideas. This with "pure" in the ancient Greek and Roman architecture and the Italian Renaissance architectural style and classical pillar type has been become a classical architecture. And in the $1760 \mathrm{~s}$ to the 19th century appeared the trend of the classical revival architecture.

In addition this time, because the European capitalism began to sprout, all kinds of new ideas constantly emerging, which including France in Europe are profoundly reflects the architectural style. Baroque, rococo style, gothic revival style began to pop up one after another.

\section{The relationship between the two countries culture and architecture}

The difference between French and Chinese construction mainly depends on the environment, closely related to geographical, economic, cultural and other factors. When we discuss and study method of traditional architecture, will inevitably involve these factors. As is known to all, building belong to the category of art, art and culture, therefore, the next I mainly on the influence of the culture of architecture.

\section{Why can't we ignore the effect of culture}

The concept of construction is not only refers to the house, it is more rich than the house. Housing only refers to the place of artificial, architecture can satisfy the various needs of human beings, however, also contain the pursuit of culture, and involves the aesthetics as well as other spiritual content. Therefore, the essence of architecture is a product of human society, is also the wisdom of human created the thought and culture.

For human prehistory, building homes and houses. With the development of economy and society, human civilization has also been progress, in the different cultures of the east and the west, and the humanism, Christianity, Buddhism, Confucianism and so on. As a kind of art, architecture also changes with time, that is to say, the new building is often with the emergence of new thoughts new civilization and appear, it is common phenomenon in the development of architecture.

Throughout the development of world civilization, regardless of where humans live on a piece of land, will form their own civilization, including thought, religion, philosophy, etc. Human society also affected the religious environment affects the art. Culture has certain stability after long time development, it is the important factor affecting the development of construction. Chinese and western buildings, all is the picture of their culture and social thought, the architect or resident or building experts in the idea of construction under the influence of their thoughts. In ancient China, the civil and military buildings are mostly based on the following two traditional thoughts: Confucianism and Taoism. Other Chinese garden architecture also reflects some of the Chinese buddhist ideas. 


\section{Both of Chinese and western culture's influence on the building}

Culture is how to affect traditional buildings? On the influence on construction, culture which contains several aspects again? Below I will discuss these problems.

First of all, it is religious belief. The Chinese put their ancestral gods; The sages, respected ancestors in the religious and historical heroes, these gods come from earth. Therefore, imperial palaces and temples, worship the gods of the buildings and even used to live together. In addition, Confucianism deeply into the Chinese construction. Confucianism attaches great importance to the ethics and the relationship of the people, is one of the main representative of Chinese culture. So Confucianism deeply reflected in Chinese traditional architecture, for example, the central axis of building embody the hierarchy, such as the Forbidden City (such as: figure 1, figure 2), on the building layout, with the form change, the technique of ups and downs, combined into a whole, it conforms to the feudal society on the function of rating system; Due to the thoughts of Confucian humility, between each building height is almost flat; Through the arrangement of buildings in a horizontal line reflect honour and power.

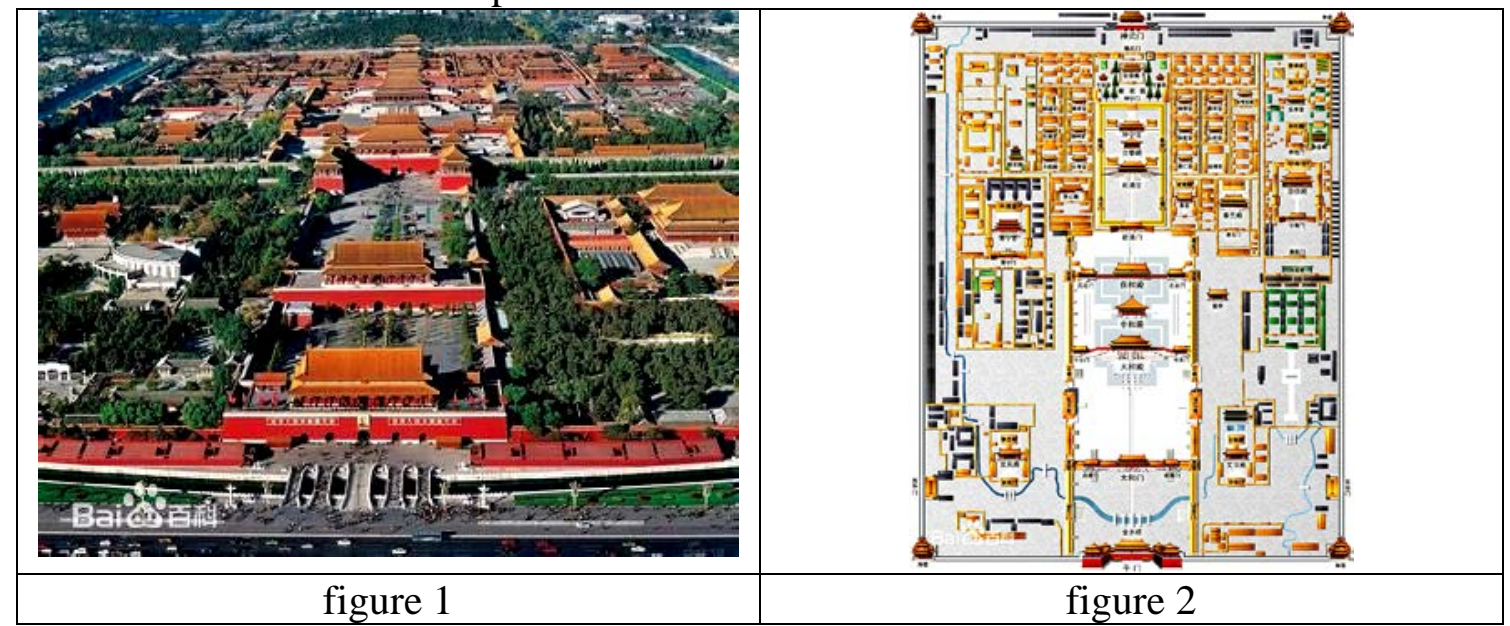

Second, in the west, control the fate of mankind are imaginary god, Jesus, Zeus, Apollo, for example, they are all gods in heaven, on high, they created humans, so humans did not infringe them. Their churches and temples are used to consecrate the supreme deity, tall, magnificent buildings just to used to represent the highest respect for them. For example, in the place DE la Concorde in Paris, stands 23 meters high weighs 230 tons of square tablet (such as: figure 3), this is the Greek authorities muhammad ali to France in 1831, the building some deeds recorded the pharaoh of Egypt, the people of Egypt in this way to honor their gods. In addition, the two countries have different perceptions of nature. According to the Chinese simple view of nature, our behavior should comply with the principle of nature and development. Such as Taoism, nature is the source of all things, should be the pursuit of harmony and unity between human and nature, and Confucianism. As a result, most of Chinese traditional architecture embodies the concept of melt into nature into the environment. A typical example is the suzhou gardens (such as: figure 4), housing, pavilions, water, plant are perfectly together. When our ancestors built these buildings, fully considered the unification of the architecture and nature. 


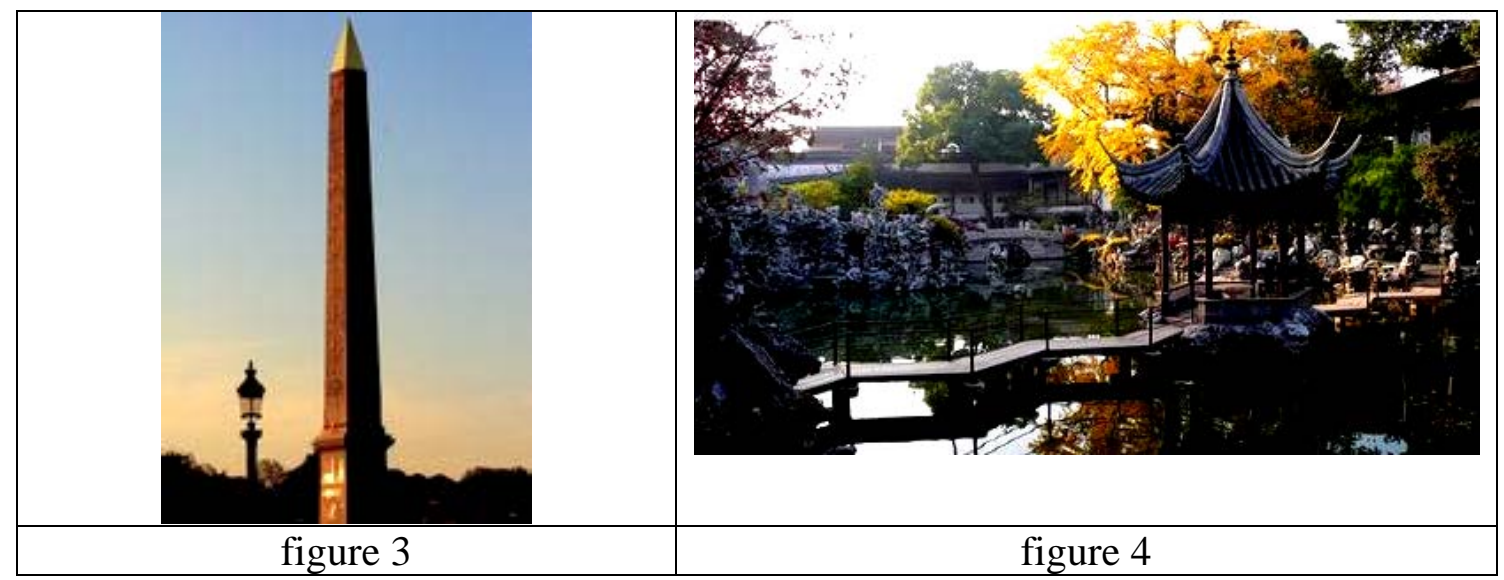

People in Europe, however, the human is the main part of the world. Inanimate objects are service for human, human will understand, change, or even to conquer them. During the Renaissance, the European thinkers believe that the relationship between man and nature are opposites between subject and object. From the point of construction materials used in Europe, the use of stone can reflect this, the strong and eternal emphasized the human have to rebuild the power of nature.

Again, the development of social thoughts between China and the west has another features: pay attention to the perceptual thinking in China, and western advocate rational thought, building, too. In China, we think the construction details of the lack of obvious characteristics, it is because there is no rational data and theoretical support. However, the western architecture attaches great importance to the geometric aesthetic and strict logic. In western architecture, geometric pattern is very common, palace of plants are unified trim molding. Versailles for typical classical style building (such as figure 5, figure 6), facade for standard classical three-step process, the facade is divided into vertical and horizontal three sections. Building left and right sides is symmetrical, shape contour neat, solemn majesty, is known as the representative is rational beauty. In front of the palace is a unique style of "style" big garden, it with Chinese classical imperial garden has a distinct style. It is completely artificial carve, extremely exquisite symmetry and geometry.

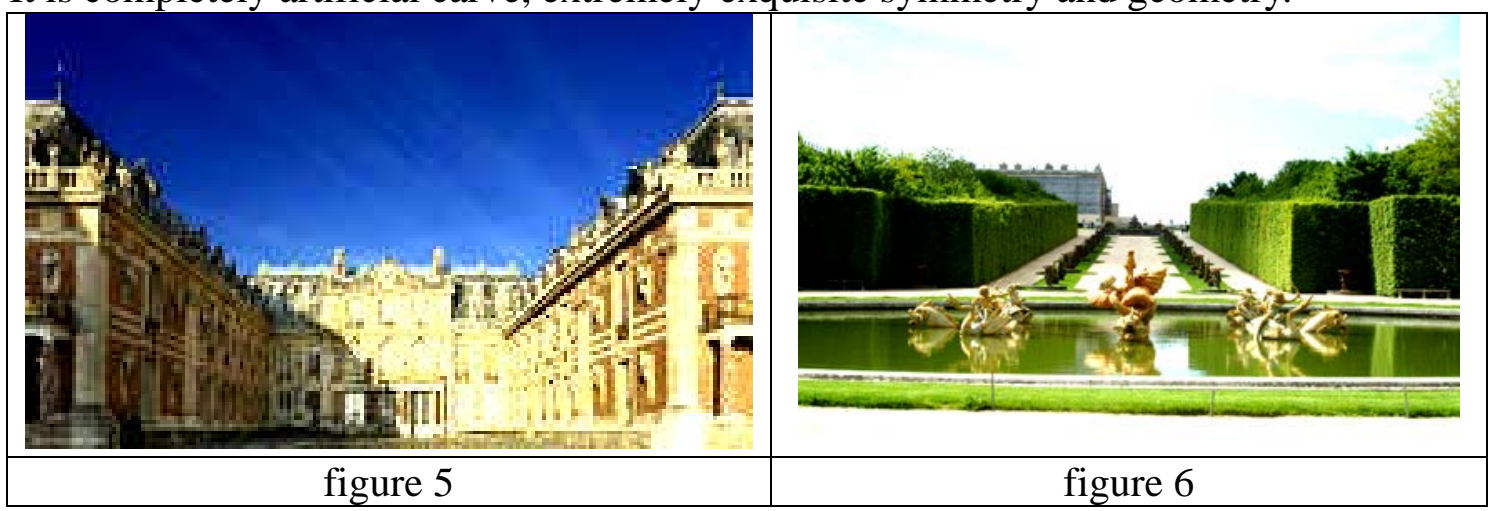

\section{Conclusion}

When we study in different parts of the building, in addition to consider the factor of environment, economy, science and technology, culture is a factor that nots allow to ignore. China and France two traditional countries shows the two different cultures; Therefore, for two completely different culture, therefore also influenced both building; This makes the method in the traditional architecture of the two countries on select material, construction type, the layout of the space, there is a big differences such as the change of the pattern. 


\section{Reference}

[1], RuXin editor, karanjia: the western architecture [M], higher education press, 2010.

[2], feng zikai with: "feng zikai about western architecture [M], hunan university press, 2010.

[3], written by Li Shujian: "the suzhou garden" [M], jilin literature publishing house, 2009.

[4], J, Zhang Hejun: the differences between the eastern and western civilization from the east and the west historic buildings "[J]," central plains cultural relic ", 2012.

[5], written by na zhang: "the Summer Palace," [M], jilin literature publishing house, 2009.

[6], LLLDD: introduction to the traditional Chinese and western architectural culture differences [J], journal of langfang normal university, 2012. 